\title{
Analisis Zat Pewarna Rhodamin B pada Gula Kapas Merah yang Dijual di Kota Mataram Tahun 2013
}

\author{
Dahlia Andayani ${ }^{1}$ dan Hardiono Adisaputra ${ }^{1}$
}

${ }^{1}$ Jurusan Ilmu Farmasi, Universitas Nahdlatul Wathan, Mataram, Indonesia

\begin{abstract}
Abstrak Zat pewarna makanan digunakan untuk merubah penampilan fisik makanan agar terlihat lebih menarik. Di Indonesia, terdapat kecendrungan penambahan zat pewarna non pangan pada beberapa jenis makanan seperti penambahan zat pewarna merah Rhodamin B merupakan senyawa kimia sintetik yang bersifat karsinogenik bagi tubuh dan banyak digunakan sebagai zat pewarna kertas dan tekstil. Penelitian ini bertujuan untuk menguji kandungan Rhodamin B pada Gula Kapas Merah yang beredar di Kota Mataram menggunakan metode uji Rhodamin B Test Kit yaitu suatu metode untuk menguji kandungan Rhodamin B pada suatu sampel makanan dengan mengamati perubahan warna yang terjadi setelah ditetesi reagen. Penelitian ini menggunakan desain penelitian deskriptif. Sampel dalam penelitian ini adalah Gula Kapas Merah. Sampel diambil menggunakan random accidental sampling. Pengujian sampel dilakukan di Laboratorium Kimia Jurusan Farmasi Fakultas Ilmu Kesehatan Universitas Nahdlatul Wathan Mataram pada bulan Agustus 2013. Data hasil penelitian diolah dengan menghitung persentase sampel yang positif dan negative mengandung Rhodamin B. Berdasarkan hasil penelitian yang diperoleh 3 sampel makanan Gula Kapas Merah ( $33 \%$ sampel ) yang positif mengandung Rhodamin B dan sebesar 67 \% sampel Gula Kapas Merah dinyatakan negatif mengandung Rhodamin B.
\end{abstract}

Kata kunci Zat pewarna, rhodamin B, gula merah.

\section{Pendahuluan}

Dalam rangka meningkatan derajat kesehatan masyarakat yang optimal, pemerintah telah melakukan berbagai upaya kesehatan seperti yang tercantum dalam pasal 47 Undang-undang Nomor 36 Tahun 2009 yaitu tentang kesehatan dengan pendekatan pemeliharaan, peningkatan kesehatan (promotif), pencegahan penyakit (preventif), Penyembuhan penyakit, dan memulihkan kesehatan yang dilaksanakan secara menyeluruh, terpadu dan berkesenimbangan. Penyelenggaran upaya kesehatan sebagai mana yang dimaksud dalam pasal 10 dilaksanakan memalui beberapa kegiatan. Salah satu kegiatan tersebut adalah pengamatan makanan.

Undang-undang Nomer 18 tahun 2012 tentang pangan menyatakan bahwa kualitas pangan yang di konsumsi harus memenuhi beberapa keriteria diantaranya adalah aman (bebas dari cemaran biologis, mikrobiologis, kimia, logam berat, dan cemaran lain yang dapat mengganggu, merugikan, dan membahayakan kesehatan manusia), bergizi, bermutu dan dapat terjangkau oleh daya beli masyarakat.

Semakin berkembangnya ilmu pengetahuan dan tekhnologi menyebabkan perubahan yang sangat besar dalam hal pengolahan pangan. Pada saaat sekarang ini, banyak bahan-bahan yang di tambahkan ke dalam makanan dan minuman untuk berbagai tujuan. Bahan-bahan yang ditambahkan ke dalam makanan tersebut disebut Bahan Tambahan Makanan (BTM).

Bahan Tambahan Makanan adalah senyawa atau campuran berbagai senyawa yang sengaja ditambahkan ke dalam makanan dan minuman dalam proses pengolahan, pengemasan dan penyimpanan dan bukan merupakan bahan (ingredient) utama. Bahan Tambahan Makanan tersebut dapat berupa pengawet, pewarna, penyedap, antioksidan, antikempal, dan pengemulsi.

Ada beberapa hal yang dapat menyebabkan suatau bahan pangan bewarna antara lain dengan penambahan zat pewarna. Peraturan mengenai penggunaan zat pewarna yang diizinkan dan yang dilarang untuk pangan diatur melalui Peraturan Mentri Kesehatan RI Nomer 033 Tahun 2012 tentang Bahan Tambahan Pangan. Akan tetapi sering sekali terjadi penyalahgunaan pemakaian zat pewarna tersebut antara lain disebabkan oleh ketidaktahuan masyarakat mengenai zat pewarna untuk pangan, dan juga karena harga zat pewarna untuk industri relatif jauh lebih murah dibandingkan dengan zat pewarna untuk pangan.

Dari hasil pemeriksaan Balai Besar POM yang diperoleh dari Laporan Tahunan Balai Besar POM tahun 2010 menyatakan bahwa dari 515 sampel yang tidak memenuhi syarat mutu, ditemukan mengandung Bahan Berbahaya sebanyak 135 sampel dengan rincian 48 sampel mie basah mengandung Boraks dan 3 sampel mengandung Formalin, 8 sampel jajanan gula kapas atau cendol dan kue basah mengandung pewarna kertas Rhodamin B, 28 sampel terasi juga mengandung pewarna kertas Rhodamin B, 7 sampel bakso mengandung Boraks, 37 sampel kerupuk mengandung Boraks, dan 3 sampel pijer/pengenyal/perenyah mengandung Boraks.

Dari hasil pemeriksaan Balai Besar POM yang di peroleh dari Laporan Tahunan Balai Besar pom Tahun 2011 menyatakan bahwa dari $2.902(14,15 \%)$ sampel tidak memenuhi persyaratan keamanan dan mutu, ditemukan mengandung Bahan Berbahaya sebanyak 151 sampel mengandung Formalin; 138 sampel mengandung Boraks; 3 sampel mengandung Methanyl Yellow; 1 sampel mengandung Auramin; 197 sampel mengandung Rhodamin B; dan 1.002 sampel mengandung cemaran mikroba 
melebihi batas; 253 sampel mengandung pengawet Benzoat, 416 sampel mengandung pemanis buatan. Dengan rincian 3.26 sampel produk yang terdiri dari mie basah, bakso, kudapan, dan makanan ringan, diketahui bahwa 94 sampel mengandung boraks dan 43 sampel mengandung Formalin, dan 40 sampel es mambo,minuman berwarna merah, jajanan gula kapas berwarna merah, sirup, jelly, kudapan, makanan ringan mengandung Rhodamin B. dan 2 sampel jajanan, minuman berwarna merah. Mengandung methanyl yellow.

Beberapa makanan dan minuman yang keamanan pangannya masih diragukan adalah makanan dan minuman yang dijual oleh pedagang kaki lima dengan harga yang murah, menarik dan bervariasi. Salah satu produk makanan dan minuman yang paling sering ditambahkan dengan zat warna adalah gula kapas. Makanan tersebut sangat digemari oleh anak-anak maupun orang dewasa karna warnanya yang menarik.

Berdasarkan dari hal tersebut di atas, penyusun ingin melakukan penelitian mengenai "Analisis zat pewarna Rhodamin B pada gula kapas merah yang di jual di Kota Mataram".

\section{Metode Penelitian}

Metode penelitian yang dipergunakan adalah metode percobaajn eksperimental. Prosedur pengujian sebagai berikut:

a. 1 sendok Teh bahan makan yang akan di uji, lalu cacah menjadi bagian-bagian kecil atau di potong menjadi kecil-kecil

b. 10 gram sampel makanan

c. Masukkan dalam beaker gelas

d. Tambahkan air mendidih sebanyak 2 sendok makan (10 ml) lalu aduk agar Rhodamin B yang ada pada makanan tertarik ke fase Air, biarkan sampai dingin

e. Ambil 1 sendok teh airnya saja, tambahkan Reagent A sebanyak 10 tetes. Kocok dengan keras (kencang) atau dapat menggunakan vortex untuk pengocokan

f. Warna merah pada larutan akan menghilang atau berkurang Drastis Intensitas warnanya

g. Tambahkan 4 tetes Reagent B, kocok kembali.

h. Amati perubahan warna bila warna merah kembali muncul atau menguat intensitas warnanya menjadi ungu atau magenta berarti sampel positif terdapat pewarna sintesis (Rhodamin B) pada makanan gula kapas merah tersebut.

i. Data yang dikumpulkan disajikan dalam bentuk tabel kemudian diolah dan dianalisis secara deskriptif yaitu :

j. Dihitung jumlah positif dan negative kandungan Rhodamin B

k. Dihitung persentase positif dan negatif kandungan Rhodamin B dan disajikan dalam bentuk diagram.

\section{Hasil dan Pembahasaan}

Hasil penelitian dapat dilihat pada Tabel 1 dan 2, sebagai berikut:
Tabel 2 Hasil Perlakuan Analisis Zat Pewarna Rhodamin B Pada Gula Kapas Merah.

\begin{tabular}{|c|c|l|l|}
\hline \multirow{2}{*}{ No } & \multirow{2}{*}{ Perlakuan } & $\begin{array}{l}\text { Hasil } \\
\text { Metode Uji } \\
\text { Rodamin } \\
\text { Test kit }\end{array}$ & \multicolumn{1}{|c|}{ Keterangan } \\
\hline 1. & Kontrol Positif & Positif (+) & \\
\hline 2. & Kontrol Negatif & Negatif (-) & \\
\hline 3. & Sampel A & Positif (+) & $\begin{array}{c}\text { Arena Buah kec. } \\
\text { Cakranegara }\end{array}$ \\
\hline 4. & Sampel B & Positif (+) & $\begin{array}{c}\text { Arena Buah kec. } \\
\text { Cakranegara }\end{array}$ \\
\hline 5. & Sampel C & Positif (+) & $\begin{array}{c}\text { Arena Buah kec. } \\
\text { Cakranegara }\end{array}$ \\
\hline 6. & Sampel D & Negatif (-) & $\begin{array}{c}\text { Udayana kec. } \\
\text { Selaparang }\end{array}$ \\
\hline 7. & Sampel E & Negatif (-) & $\begin{array}{c}\text { Udayana kec. } \\
\text { Selaparang }\end{array}$ \\
\hline 8. & Sampel F & Negatif (-) & $\begin{array}{c}\text { Udayana kec. } \\
\text { Selaparang }\end{array}$ \\
\hline 9. & Sampel G & Negatif (-) & $\begin{array}{c}\text { Loang Balok kec. } \\
\text { Sekarbela }\end{array}$ \\
\hline 10. & Sampel H & Negatif (-) & $\begin{array}{c}\text { Loang Balok kec. } \\
\text { Sekarbela }\end{array}$ \\
\hline 11. & Sampel I & Negatif (-) & $\begin{array}{c}\text { Loang Balok kec. } \\
\text { Sekarbela }\end{array}$ \\
\hline
\end{tabular}

Tabel 2. Hasil Analisis Zat Pewarna Rhodamin B Pada Gula Kapas Merah Yang Di Jual Di Kota Mataram Tahun 2013.

\begin{tabular}{|c|c|c|c|}
\hline \multirow{2}{*}{ No } & \multirow{2}{*}{ Sampel } & \multicolumn{2}{|c|}{ Jumlah Sampel } \\
\hline & & Positif & Negatif \\
\hline 1 & Arena Buah kec. Cakranegara & 1 & 0 \\
\hline 2 & Arena Buah kec. Cakranegara & 1 & 0 \\
\hline 3 & Arena Buah kec. Cakranegara & 1 & 0 \\
\hline 4 & Udayana kec. Selaparang & 0 & 1 \\
\hline 5 & Udayana kec. Selaparang & 0 & 1 \\
\hline 6 & Udayana kec. Selaparang & 0 & 1 \\
\hline 7 & Loang Balok kec. Sekarbela & 0 & 1 \\
\hline 8 & Loang Balok kec. Sekarbela & 0 & 1 \\
\hline 9 & Loang Balok kec. Sekarbela & 0 & 1 \\
\hline & TOTAL & 3 & 6 \\
\hline & PERSENTASE & $33 \%$ & $67 \%$ \\
\hline
\end{tabular}

Rhodamin B merupakan zat warna sintesis berbentuk serbuk kristal, tidak berbau, berwarna merah keunguan, dalam bentuk larutan berwarna merah terang berpendar (berfluoresensi). Rhodamin B sangat mudah larut dalam air dan dalam alkohol, sukar larut dalam asam encer dan dalam larutan Alkali. Menurut Peraturan Menteri Kesehatan (Permenkes) No.033 tahun 2012 tentang Bahan Tambahan menetapkan 30 zat pewarna berbahaya Rhodamin B termasuk salah satu zat pewarna yang dinyatakan sebagai zat pewarna berbahaya dan dilarang digunakan pada produk pangan. Rhodamin B merupakan salah satu zat pewarna kimia sintetik yang mampu memberikan aksen warna merah 
pada suatu bahan seperti kertas dan tekstil, tetapi sering terjadi penyalahgunaan sebagai pewarna makanan. Penambahan Rhodamin B dengan kadar sekecil apapun pada makanan tidak dibenarkan karena bersipat karsinogen yang secara perlahan terakumulasi dalam tubuh hingga menyebabkan kematian.

Kemasan Rhodamin B Test Kit terdiri dari dua larutan preaksi atau reagen yaitu reagen A yang berisi larutan pereaksi SbCl5 (StibiumClorida) dalam $\mathrm{HCl} 5 \mathrm{~N}$ dan reagen B yang berisi larutan pereaksi toluene (Metil Benzena). Suatu bahan makanan yang positif mengandung Rhodamin B ditandai dengan tidak menghilangnya warna merah larutan saat penambahan reagen A yang dilakukan dengan pengocokan kuat. Warna merah kembali muncul dengan intensitas warna yang semakin menguat hingga menjadi warna ungu kemerahan saat penambahan reagen $\mathrm{B}$.

Cairan akhir hasil reaksi akan terlihat memisah membentuk dua lapisan saat penambahan reagen $B$. hal ini disebabkan karena reagen $\mathrm{A}(\mathrm{SbCl5})$ dan reagen $\mathrm{B}$ (C6H5CH3) memiliki bobot jenis yang berbeda, hal ini yang mengakibatkan reagen $\mathrm{A}$ berada pada lapisan bawah cairan dan reagen $\mathrm{B}$ menjadi lapisan atas cairan.

Bentuk penyalahgunaan Rhodamin B banyak ditemukan pada makanan-makanan bewarna merah khususnya Gula Kapas Merah yang biasanya di jajankan oleh kalangan masyarakat dari anak-anak, dewasa sampai orang tua. Yang disebut dengan Gula Kapas Merah yaitu proses pembuatannya memang menggunakan gula yang diberi pewarna makanan namun komposisinya memang sangat kecil. Di samping sebagai pewarna, Rhodamin B digunakan untuk memperbaiki tekstur warna sehingga menghasilkan warna lebih menarik. Ada beberapa faktor yang menjadi penyebab penyalah gunaan Rhodamin B oleh produsen atau penjual makanan yaitu Rhodamin B lebih mudah diperoleh yang tersedia dipasaran dalam bentuk kemasan.harganya relatif lebih murah atau dapat juga disebabkan karna produsen atau penjual makanan tidak mengetahui tentang larangan atau bahaya Rhodamin B. Pengujian secara kualitatif pada bahan makanan yang di duga mengandung Rhodamin $\mathrm{B}$ perlu dilakukan untuk mengidentifikasi ada tidaknya kandungan rhodamin B dari bahan makanan. Ada beberapa metode yang digunakan untuk menguji ada tidaknya kandungan Rhodamin B pada makanan yaitu metode Kromatografi Lapis Tipis dan metode Rhodamin Test Kit.

Berdasarkan Laporan Balai Besar POM di Mataram Tahun 2011 menyatakan bahwa masih terdapat sampel gula kapas merah yang mengandung Rhodamin B. Hal ini sesuai dengan hasil penelitian ini yaitu sebagian gula kapas merah masih terdapat menggunakan zat pewarna Rhodamin B. Kemungkinan para penjual belum sadar akan bahayanya Rhodamin B bagi kesehatan sehingga masih ada penjual yang menggunakan Rhodamin B untuk mewarnai makanan. Meskipun demikian, masyarakat tetap lebih berhati-hati dalam mengkonsumsi gula kapas merah. Pengamatan organoleptik penting di lakukan khususnya pada gula kapas merah yang memiliki tekstur pintalan gula kapas yang sangat menarik dan bewarna merah yang mana cirri-ciri fisik gula kapas merah cerah dan terang seperti ini sesuai dengan cirri-ciri yang positif mengandung Rhodamin B. Sebaiknya produsen atau pedagang menggunakan bahan pewarna yang di perbolehkan seperti Cochineal red ( karmin ). Sehingga untuk pihak Dinas Kota perlu melakukan pengawasan terhadap makanan yang beredar bebas dan tidak memiliki izin.
Menurut Undang-Undang Republik Indonesia Nomer 18 Tahun 2012 Tentang Pangan pasal 136 setiap orang yang melakukan produksi pangan untuk diedarkan yang dengan sengaja menggunakan bahan yang dilarang untuk digunakan sebagai bahan tambahan pangan dipidana dengan pidana penjara paling lama 5 (lima) tahun atau denda paling banyak 10.000.000.000 (sepuluh miliar rupiah)

Produsen atau pedagang gula kapas merah masih sangat meminati pewarna sintetis untuk makanan yaitu pertama masalah harga. Pewarna kimia tersebut dijual dengan harga yang jauh lebih murah dibandingkan dengan pewarna alami. Masalah ini tentu saja sangat diperhatikan oleh produsen, mengingat daya beli masyarakat Indonesia yang masih cukup rendah. Factor kedua adalah stabilitas. Pewarna sintetis memiliki tingkat stabilitas yang lebih baik, sehingga warnanya tetap cerah meskipun sudah mengalami proses pengolahan dan pemanasan. Sedangkan pewarna alami mudah mengalami degradasi atau pemudaran pada saat diolah dan disimpan. Misalnya gula kapas merah yang menggunakan pewarna alami, maka warna tersebut akan segera pudar manakala mengalami proses pembuatan dan pembungkusan.

Penelitian ini diawali dengan survey lokasi penelitian yaitu diseluruh pedagang gula kapas merah disetiap kecamatan yang beredar di Kota Mataram untuk melihat dan menghitung jumlah makanan atau penjual gula kapas merah dilingkungan kota mataram tersebut. Dari setiap wilayah yang ditentukan berdasarkan dengan hasil survey yang di temukan, kemudian diambil beberapa sampel gula kapas merah untuk dianalisis kandungan Rhodamin B.

Cara pembelian sampel yaitu dengan cara acak lain hari dan hari 1 langsung membeli 3 sampel sekaligus di wilayah Loang Balok. Hari ke 2 di wilayah Udayana langsung beli 3 sampel. Hari ke 3 di wilayah Arena Buah dan beli 3 sampel sekaligus.

Berdasarkan hasil penelitian Analisis kandungan Rhodamin B pada sampel Gula Kapas Merah yang beredar di kota mataram seperti terlihat pada tabel 4 yaitu hasil pengujian sampel gula kapas merah yang negatif mengandung Rhodamin B ditandai dengan tidak terjadinya warna merah ( warna merah yang menghilang ). Saat penambahan reagen A sebanyak 10 tetes Reagen A masih berwarna merah, saat penambahan Reagen B 4 tetes warna merah langsung memudar dan menghilang.

Hasil penelitian Analisis Zat Pewarna Rhodamin B Pada Gula Kapas Merah Yang Di Jual Di Kota Mataram Tahun 2013 membuktikan dugaan bahwa masih ada terdapat gula kapas merah yang mengandung Rhodamin B. Ada 1 sampel dari pedagang di Arena Buah Kecamatan Cakranegara terdapat positif mengandung Rhodamin B. Sedangkan 2 sampel dari pedagang di Udayana dan di Loang Balok menghasilkan sampel negatif mengandung Rhodamin B..

\section{Kesimpulan}

Hasil uji kualitatif kandungan Rhodamin B pada Gula Kapas Merah yang beredar di kota Mataram adalah sebanyak 9 sampel gula kapas merah yang terdapat positif ada 3 sampel ( $33 \%$ sampel) yang mengandung Rhodamin B dan 6 sampel lainnya (67 \% sampel) tidak mengandung Rhodamin B. 


\section{Daftar Pustaka}

Baliwati, dkk. 2004. Pengantar pangan dan gizi. Jakarta : Penebar Swadaya.

Depkes R.I, 1992 Undang-Undang RI No. 23 Tahun 1992. Jakarta : Tentang Kesehatan.

Januansyah, Topan, 2011. Karya tulis ilmiah identifikasi kandungan boraks dalam bakso daging pada jajanan anak sekolah yang beredar di sekolah dasar koata mataram. Mataram : Program Studi Farmasi (DIII) Fakultas Ilmu Kesehatan Universitas Nahdatul Wathan Mataram Tahun 2011.

Kusnandar, dkk, 2008. Teknologi Proses Produk Minuman Nata De Coco Dalam Cup. www.unhas.ac.id. Diakses tanggal 5 April 2013.

Ningsih, sulistia, 2011. Karya tulis ilmiah uji kualitatif kandungan rodamin $b$ pada sepuluh jajanan pasar yang beredar di pasar kebun roek kecamatan ampenan. Mataram : Program Studi Farmasi (DIII) Fakultas Ilmu Kesehatan Universitas Nahdatul Wathan Mataram Tahun 2011.

Notoatmodjo, Soekidjo. 2005. Metodologi Penelitian Kesehatan. Jakarta : Rineka Cipta.

Slamat, 1994. Kesehatan Lingkungan. Yogyakarta : Gajah Mada University.

Syah, dkk. 2005. Manfaat dan Bahaya Bahan Tambahan Pakan. Bogor : Himpunan Alumni Fakultas Teknologi Pertanian Institute Pertanian Bogor. 